\title{
PRODUÇÃO E ESTADO NUTRICIONAL DE POVOAMENTOS DE Eucalyptus grandis, EM SEGUNDA ROTAÇÃO, EM RESPOSTA À ADUBAÇÃO POTÁSSICA ${ }^{1}$
}

\author{
Geraldo Erli de Faria², Nairam Félix de Barros ${ }^{3}$, Roberto Ferreira de Novais ${ }^{3}$, Júlio César Lima ${ }^{3}$ e \\ José Luiz Teixeira ${ }^{3}$
}

\begin{abstract}
RESUMO - A condução de brotação de cepas é uma técnica corriqueira nas plantações de eucalipto no Brasil. Contudo, a queda de produtividade da primeira para a segunda rotação tem sido freqüentemente observada, e a deficiência de nutrientes minerais é uma das possíveis causas deste fato. O objetivo deste estudo foi avaliar o efeito residual de doses de K sobre o estado nutricional, o balanço de $\mathrm{K}$ e a produção de Eucalyptus grandis, em segunda rotação, assim como as quantidades de N, P, K, Ca e Mg acumuladas na copa e no tronco. Doses de 30, 60,120 e $240 \mathrm{~kg} / \mathrm{ha}$ de $\mathrm{K}_{2} \mathrm{O}$, na forma de $\mathrm{KCl}$, foram aplicadas a lanço em toda a área e incorporadas ao solo antes do plantio. Incluiu-se, ainda, a parcela sem aplicação de K. Na primeira rotação as árvores foram cortadas aos 78 meses. Em seguida, fez-se a condução de um broto por cepa. Aos 80 meses após o primeiro corte, ou seja, já na segunda rotação, foram avaliados o volume do tronco, a produção de matéria seca e o conteúdo de nutrientes na árvore e na manta orgânica e os teores de nutrientes no solo. A maior dose de $\mathrm{K}$, aplicada na implantação do povoamento, causou aumento da ordem de $54 \%$ no volume e na matéria seca dos troncos das árvores na segunda rotação, em comparação com o tratamento sem adubação. Nessas condições, a diferença no acúmulo de $\mathrm{N}, \mathrm{P}, \mathrm{Ca}$ e Mg nas árvores foi, em média, de 69\%. Da primeira para a segunda rotação houve decréscimo médio de $52 \%$ na produtividade, atribuído à exportação de nutrientes, em especial de K, na rotação anterior, ocasionando a redução na fertilidade do solo.
\end{abstract}

Palavras-chave: Eucalipto, brotação, eficiência nutricional e sustentabilidade florestal.

\section{YIELD AND NUTRITIONAL STATUS OF COPPICED EUCALYPTUS STANDS AS AFFECTED BY POTASSIUM APPLIED AT PLANTING TIME}

\begin{abstract}
Coppicing is a common technique used in eucalyptus plantations in Brazil. However, a productivity reduction from the first to the second rotation has frequently been observed, with deficiency of mineral nutrients being a possible reason for this decrease. This study evaluates the residual effect of $K$, applied at planting time, on yield and nutritional status of Eucalyptus grandis stands regenerated by coppicing. The trial was carried out on a Red Yellow Latosol, in the cerrado region of Minas Gerais Brazil in 1981. Five rates of K (0; 30; 60; 120, and $240 \mathrm{~kg} / \mathrm{ha} \mathrm{K}_{2} \mathrm{O}$ ) were broadcast applied and incorporated into the soil prior to seedling planting. Report results, corresponding to the second rotation, are presented in this paper. Assessments were conducted 80 months after harvesting. Potassium applied at the beginning of the first rotation increased stem volume and biomass of the second rotation (coppices), with the highest difference (54\%) observed between control and the rate of $240 \mathrm{~kg} / \mathrm{ha} \mathrm{K}_{2} \mathrm{O}$. Similarly, the amount of $\mathrm{K}$ in the fertilized trees was around $69 \%$ higher than those of the control plot. In spite of that, yield of the second rotation was about 52\% lower than in the first rotation. This reduction in productivity was attributed to the decrease of $K$ in the site as well as of other nutrients such as $P, C a$ and $\mathrm{Mg}$, as indicated by the ratio between yield and nutrient amount in the trees.
\end{abstract}

Key words: Coppicing, second rotation, Eucalyptus grandis, nutritional efficiency.

1 Recebido para publicação em 19.12.2001.

Aceito para publicação em 6.11.2002.

2 Engenheiro Florestal, M.S. em Ciência Florestal, Dep. de Engenharia Florestal da Universidade Federal de Viçosa - UFV; ${ }^{3}$ Dep. de Solos da UFV, 36571-000 Viçosa-MG, Bolsistas do CNPq. 


\section{INTRODUÇÃO}

A condução da brotação de cepas, após o corte raso da floresta, é aplicável a espécies florestais que têm capacidade de regenerar vegetativamente. Esse sistema de condução de povoamentos florestais, denominado de talhadia, é adequado à maioria das espécies do gênero Eucalyptus, que apresentam a capacidade de lançar brotos em razão das gemas adventícias presentes no tronco. Esses se desenvolvem e podem ser conduzidos para reconstituir o povoamento. Tal característica é desejável, pois a partir de um único plantio pode-se obter uma ou mais colheitas, com redução significativa de gastos com reforma. Entretanto, em muitas regiões brasileiras a produtividade de povoamentos de eucalipto em regime de talhadia tem sido inferior àquela observada no primeiro ciclo, o que tem levado muitas empresas florestais a optarem pela reforma dos povoamentos.

Se as propriedades físicas do solo e a condição climática não variarem de uma rotação para outra, a redução da produtividade pode ser atribuída à deficiência de nutrientes, decorrente da exportação de nutrientes por meio da colheita dos troncos. A reaplicação de fertilizantes às brotações deveria levar a um novo período de elevada taxa de crescimento, o que nem sempre tem sido observado. Barros et al. (1990) atribuem tais resultados ao desconhecimento da dinâmica de crescimento e da remobilização de nutrientes do sistema radicular e à falta de estratégia eficaz para a adubação de touças. A definição de uma estratégia de adubação de brotação requer o conhecimento do potencial produtivo do sítio, da taxa de crescimento da floresta, da eficiência de utilização de nutrientes e da disponibilidade de nutrientes no solo (Barros et al., 1997). Poucos são os trabalhos realizados no Brasil sobre adubação de brotação. Stape \& Benedetti (1997) relataram ganho de $4,45 \mathrm{~m}^{3} / \mathrm{h} /$ ano para produção de $E$. grandis pela adubação, tendo a aplicação de NK sido responsável pelos melhores resultados. Esses autores não distinguiram, contudo, qual dos dois nutrientes mais contribuiu para esse ganho. Diante dos resultados relatados por Gama-Rodrigues (1997) e da menor intensidade de resposta de eucalipto a nitrogênio (Barros et al., 1990), pode-se levantar a hipótese de que o $\mathrm{K}$ tem sido o nutriente mais importante ao se fazer a adubação de brotações.

Os objetivos deste trabalho foram avaliar o efeito residual de doses de potássio, aplicadas no plantio, sobre o estado nutricional e a produção de povoamentos de
E. grandis em segunda rotação; calcular o balanço de potássio no sistema; e verificar sua relação com os conteúdos de N, P, Ca e Mg na parte aérea da árvore.

\section{MATERIAL E MÉTODOS}

O trabalho foi conduzido no município de Itamarandiba $\left(17^{\circ} 41^{\prime}\right.$ latitude S; $42^{\circ} 31^{\prime}$ longitude W), Minas Gerais, em povoamentos de Eucalyptus grandis W. Hill ex Maiden, com mudas formadas a partir de sementes, estabelecidos em dezembro de 1981, em Latossolo Vermelho-Amarelo álico textura argilosa. Os tratamentos consistiram de cinco doses de $\mathrm{K}(0,30,60$, 120 e $240 \mathrm{~kg} / \mathrm{ha}$ de $\mathrm{K}_{2} \mathrm{O}$ ) na forma de $\mathrm{KCl}$, aplicadas a lanço e incorporadas ao solo, nos $20 \mathrm{~cm}$ superficiais, antes do plantio. Os tratamentos foram dispostos em blocos casualizados, com seis repetições. As parcelas experimentais tinham área de $600 \mathrm{~m}^{2}$ e 100 plantas. Após o preparo do solo, foram aplicadas $2 \mathrm{t} / \mathrm{ha}$ de fosfato-dearaxá, a lanço e incorporadas. À época de plantio das mudas, foram aplicados por cova $100 \mathrm{~g}$ de superfosfato simples, $3 \mathrm{~g}$ de bórax e $5 \mathrm{~g}$ de sulfato de zinco. Foram aplicados ainda $75 \mathrm{~kg} / \mathrm{ha}$ de nitrogênio, parcelados em quantidades iguais, aos 45, 90 e 270 dias após o plantio. Após 78 meses, o povoamento foi cortado e avaliado por Galo (1993). Os resíduos da colheita permaneceram no campo, no local de cada parcela, e a segunda rotação foi então conduzida. Nesta rotação, fez-se a aplicação de $189 \mathrm{~kg} / \mathrm{ha}$ da formulação 5-10-30 na linha de plantio, em todas as parcelas. Nove meses após o corte procedeu-se à desbrota, deixando-se um broto por cepa. Oitenta meses após o primeiro corte, novas avaliações foram realizadas como parte deste estudo. Cinco repetições foram avaliadas nesta fase. Mediu-se o diâmetro à altura do peito (DAP) de 64 árvores e abateu-se, por parcela, uma árvore com diâmetro correspondente ao da árvore média do respectivo tratamento. Procedeu-se à cubagem das árvores pelo método de Smalian, utilizando a altura, o diâmetro e a espessura de casca na base e a 25, 50, 75 e $100 \%$ da altura comercial. O peso de material fresco do lenho, da casca, das folhas, dos galhos e das raízes foi determinado no campo, e destes componentes coletaramse amostras para determinação do peso da matéria seca e para análise química. As amostras do tronco consistiram de discos coletados, com casca, na base e a $25,50,75$ e $100 \%$ da altura comercial. Para análise química coletouse uma amostra de "pó-de-serra" obtida por meio de corte com motosserra até o meio da seção transversal, de $50 \mathrm{em} 50 \mathrm{~cm}$, ao longo do tronco. 
Para amostragem do sistema radicular, demarcouse, ao lado da árvore selecionada, um retângulo com superfície igual a um quarto $\left(1,5 \mathrm{~m}^{2}\right)$ da área útil de cada árvore. A manta orgânica desta área foi retirada e coletaram-se as raízes sobre a superfície do solo e por entre o material em decomposição, como também nas camadas de 0-10, 10-20, 20-40, 40-60 e 60-100 cm. O solo, juntamente com as raízes, foi passado em peneira de malha de $2 \mathrm{~mm}$, procedendo-se à separação das raízes, de acordo com o diâmetro, em grossas ( $>5 \mathrm{~mm}$ ), médias $(2-5 \mathrm{~mm})$ e finas $(<2 \mathrm{~mm})$. A classificação das raízes foi feita visualmente, comparando-as com gabaritos dos respectivos diâmetros-limites. A massa de raízes vivas, para uma mesma profundidade e classe de diâmetro, foi determinada. A raiz pivotante foi retirada até a profundidade de $1 \mathrm{~m}$, removendo-se o solo aderido. As amostras da raiz pivotante foram retiradas por meio de cortes transversais com motosserra, obtendo-se três discos (base, meio e topo) com diferentes diâmetros e recolhendo-se o "pó-de-serra".

As amostras da manta orgânica foram coletadas ao acaso, em quatro pontos de cada parcela, em uma área de $0,25 \mathrm{~m}^{2}$, delimitada por um gabarito de $50 \times 50 \mathrm{~cm}$. Após a obtenção do peso total das amostras de manta orgânica esta foi homogeneizada, para obter uma subamostra composta.

As amostras de solo foram coletadas na mesma época em que as demais avaliações foram realizadas à distância de $50 \mathrm{~cm}$ do tronco, na linha de plantio, e mais uma entre as linhas de plantio de 0-10, 10-20, 20-40, 40-60, 60-100 e 100-150 cm de profundidade. Em cada situação foram coletadas quatro amostras simples, para formar uma composta, por profundidade e por parcela. Nessas amostras foram determinados o $\mathrm{pH}$ em água, o $\mathrm{P}$ e o $\mathrm{K}$ extraídos com Mehlich-1, $\mathrm{Ca}^{+2}, \mathrm{Mg}^{+2}$ e $\mathrm{Al}^{3+}$ extraídos com $\mathrm{KCl} 1 \mathrm{~mol} / \mathrm{L}$ e $(\mathrm{H}+\mathrm{Al})$ por extração com $\mathrm{Ca}(\mathrm{OAc})_{2}$ 0,5 mol/L, a pH 7,0, conforme EMBRAPA (1997).

Nas amostras de tecido vegetal e manta orgânica, foram determinados o teor de $\mathrm{P}$ por colorimetria (Braga \& Defelipo, 1974); o de K por fotometria de emissão de chama (ASSOCIATIONS OF OFFICIAL ANALYTICAL CHEMISTS - A.O.A.C, 1975); Ca e Mg por espectrofotometria de absorção atômica (A.O.A.C., 1975); o de $\mathrm{N}$ total pelo método semimicro Kjeldahl. Estimou-se o conteúdo de cada nutriente, multiplicando-se o seu teor pelo peso de matéria seca do componente em questão, e a eficiência de utilização dos nutrientes, por meio da relação entre o peso de matéria seca e o conteúdo de nutrientes de cada componente da árvore.

Os dados foram submetidos à análise de variância e ajustaram-se regressões, relacionando-se características de crescimento com as doses de $\mathrm{K}$ aplicadas.

\section{RESULTADOS E DISCUSSÃO}

\subsection{Produção em Volume e em Matéria Seca}

A produção volumétrica $(\mathrm{V})$ e de biomassa do tronco (B) da brotação foi significativamente influenciada pelas doses de $\mathrm{K}$ aplicadas (Quadro 1), sendo representadas, respectivamente, pelas equações: $\mathrm{V}=87,44+0,46321 \mathrm{~K}-$ $0,00111 \mathrm{~K}^{2}\left(\mathrm{R}^{2}=0,98 ; \mathrm{p}<0,01\right)$ e $\mathrm{B}=42,399+0,24796 \mathrm{~K}$ $-0,00065 \mathrm{~K}^{2}\left(\mathrm{R}^{2}=0,97 ; \mathrm{p}<0,05\right)$. Comportamento semelhante também foi observado para a biomassa total (BT), que foi representada pela seguinte equação: $\mathrm{BT}=$ $93,12+0,20625 \mathrm{~K}\left(\mathrm{R}^{2}=0,90 ; \mathrm{p}<0,01\right)$.

A produção volumétrica e o incremento médio anual (IMA) da segunda rotação apresentaram ganho de 54\%, ao comparar a maior dose com a testemunha. Para matéria seca total a diferença entre esses dois tratamentos foi de $63,7 \%$. Ao aplicar o K aumentou-se a quantidade de copa (o que implica um aumento de área foliar) das árvores (a diferença entre biomassa de copa desses dois tratamentos foi de 108,9\%) e, conseqüentemente, sua captação de energia. Resultados semelhantes foram também encontrados no cerrado por Leal et al. (1988) e Miranda et al. (1998a), ao compararem árvores de eucalipto adubadas com não-adubadas. Ressalta-se que neste experimento, na primeira rotação, a maior dose proporcionou ganhos de 98,6 e de $86,7 \%$ na biomassa da parte aérea e da copa, respectivamente, em relação à testemunha (Galo, 1993).

As raízes foram outro componente das árvores cuja adubação potássica afetou acentuadamente (cerca de $100 \%$ ) a produção de biomassa (Quadro 1). Portanto, a adubação potássica contribuiu, de um lado, para a exploração de maiores volumes de solo, aumentando a possibilidade de maior absorção de água e de nutrientes, e, por outro, para a maior absorção de energia solar pela maior quantidade de copa. A resultante desses processos foi a maior produção das plantas adubadas (Quadro 1). Outro possível efeito da adubação potássica, não medido neste experimento, foi o melhor controle da abertura e do fechamento dos estômatos das árvores adubadas, o que resultou em aumento da eficiência de uso de água

R. Árvore, Viçosa-MG, v.26, n.5, p.577-584, 2002 
pelas plantas, conforme relatado por Teixeira et al. (1995) para várias espécies de eucalipto. Tal fato implica maior produção de matéria seca das plantas adubadas por unidade de volume de água transpirada, em comparação com as plantas não-adubadas.

A proporção de matéria seca alocada nas raízes variou de 25,2 a 34,1\% em relação à matéria seca total, decrescendo à medida que se aplicou potássio. Vários autores (Chapin, 1988; McDonald et al., 1991) relataram o decréscimo relativo de raízes com o aumento da disponibilidade de nutrientes e de água. Essa proporção é comparável com os valores encontrados por Reis et al. (1985) e Ladeira (1999), para eucalipto cultivado sob condições de cerrado.

Ao comparar a produtividade da primeira rotação (1 $\left.{ }^{a} \mathrm{R}\right)$ com a da segunda (2 $\mathrm{a}$ R), verifica-se que a produção no tratamento não-fertilizado atingiu $63 \%$ do IMA da primeira rotação. Para os tratamentos com maiores doses de K, o IMA da segunda rotação foi menor que o da primeira. Por exemplo, no caso da dose de $240 \mathrm{~kg} / \mathrm{ha}$ de $\mathrm{K}_{2} \mathrm{O}$, o IMA da segunda rotação foi de apenas $46 \%$ do IMA da primeira, com decréscimo de $54 \%$ na produtividade. Considerando todos os tratamentos, a redução média na produtividade em volume foi de $52 \%$. Portanto, a aplicação de $189 \mathrm{~kg} / \mathrm{ha}$ da fórmula 05-10-30, em todos os tratamentos, não foi suficiente para evitar o decréscimo de produtividade na magnitude prevista por Galo (1993) de 50 a $60 \%$ na segunda rotação, uma vez que o $\mathrm{K}$ e outros nutrientes não foram repostos em quantidades satisfatórias. Respostas de brotações de eucalipto à aplicação de potássio têm sido freqüentes (Gonçalves, 1990; Gava, 1997; Stape \& Benedetti,1997) e podem ser mais acentuadas se os resíduos da colheita forem retirados da área. Ao final da primeira rotação deste experimento, Galo (1993) verificou que o conteúdo de K na copa das árvores foi proporcional às doses de $\mathrm{K}$ aplicadas, variando de 31,5 a $34,7 \%$ do total do nutriente absorvido e acumulado na parte aérea. Miranda et al. (1998b), ao avaliarem o efeito da distribuição da galhada da rotação anterior em povoamentos de eucalipto em regime de talhadia aliada à fertilização mineral, constataram um ganho adicional em volume de $86,1 \%$, o que indica a importância da manutenção dos resíduos florestais na área para redução da perda de produtividade florestal na região do Vale do Jequitinhonha.

\subsection{Nutriente na Matéria Seca e Eficiência Nutricional}

Com o aumento da dose de $\mathrm{K}$ na implantação, de modo geral, houve tendência de maior acúmulo de N, P, $\mathrm{Ca}$ e Mg na copa e no tronco das árvores (Quadro 2). Segundo Reis \& Barros (1990), a adição de fertilizante a solo pobre em um ou mais nutrientes normalmente resulta em ganhos de crescimento e, consequientemente, em maior absorção de todos os nutrientes pelas árvores, e não só daqueles aplicados. A exemplo do que tem sido registrado na literatura para eucalipto (Reis \& Barros, 1990; Gonçalves et al., 1997), os nutrientes mais acumulados pelas brotações foram $\mathrm{N}$ e $\mathrm{Ca}$, com valores variando de 55,1 a 63,5 e de 64,8 a $73,6 \%$, respectivamente, para copa e tronco, em relação ao total acumulado na parte aérea. $\mathrm{O}$ maior conteúdo de $\mathrm{Ca}$ no tronco, mais do que o de qualquer outro nutriente, deve-se à sua elevada concentração na casca (Texeira et al., 1989 e Reis \& Barros, 1990).

Quadro 1 - Volume de tronco e matéria seca dos componentes da árvore e da manta orgânica de brotações de $E$. grandis, aos 80 meses de idade, influenciados por doses de K na implantação, e comparação entre a produtividade observada na primeira (1 1 aR) $)^{1 /}$ e na segunda rotação $(2 \mathrm{a}$ R)

Table 1 - Stem volume and dry matter of tree components and forest floor of an 80-month-old stand of $\boldsymbol{E}$. grandis managed by coppicing, as affected by $K$ rates applied at planting time, and productivity from the first and the second rotation

\begin{tabular}{|c|c|c|c|c|c|c|c|c|}
\hline \multirow{2}{*}{ Dose de $\mathrm{K}_{2} \mathrm{O}$} & \multirow{2}{*}{ Volume Tronco } & \multirow{2}{*}{$\begin{array}{c}\text { IMA } \\
1^{a} \mathrm{R}\end{array}$} & \multirow{2}{*}{$\begin{array}{c}\text { IMA } \\
2^{2} \mathrm{R}\end{array}$} & \multirow{2}{*}{$2^{\underline{a}} \mathrm{R} / 1^{-\underline{a}} \mathrm{R}$} & \multicolumn{4}{|c|}{ Matéria Seca } \\
\hline & & & & & Copa & Tronco & Manta Orgânica & Raízes \\
\hline$(\mathrm{kg} / \mathrm{ha})$ & $\left(\mathrm{m}^{3} / \mathrm{ha}\right)$ & \multicolumn{2}{|c|}{$\left(\mathrm{m}^{3} / \mathrm{ha} / \mathrm{ano}\right)$} & $(\%)$ & \multicolumn{4}{|c|}{$(\mathrm{Mg} / \mathrm{ha})$} \\
\hline 0 & 87,9 & 20,5 & 12,9 & 63 & 4,5 & 41,9 & 17,3 & 21,5 \\
\hline 30 & 102,3 & 28,8 & 15,0 & 52 & 7,8 & 51,5 & 15,1 & 31,1 \\
\hline 60 & 107,1 & 32,5 & 15,8 & 49 & 7,8 & 52,5 & 15,3 & 35,2 \\
\hline 120 & 130,1 & 37,9 & 19,1 & 50 & 9,1 & 63,8 & 17,5 & 33,7 \\
\hline 240 & 135,5 & 43,0 & 19,9 & 46 & 9,4 & 64,7 & 22,3 & 43,1 \\
\hline
\end{tabular}

${ }^{1 /}$ Fonte: GALO (1993).

IMA = incremento médio anual e DAP = diâmetro à altura do peito $(1,30 \mathrm{~m})$. 
Quadro 2 - Quantidades de N, P, Ca e Mg na copa e no tronco de brotações de E. grandis, aos 80 meses de idade, influenciadas pelas doses de $\mathrm{K}$ aplicadas na implantação do povoamento

Table 2 - Amount of $N, P, C a$ and $M g$ in the canopy and stem of 80 month-old, E. grandis coppices, as affected by $K$ rates, applied at planting time

\begin{tabular}{|c|c|c|c|c|c|c|c|c|}
\hline \multirow{2}{*}{ Dose de $\mathrm{K}_{2} \mathrm{O}$} & \multicolumn{2}{|c|}{ Nitrogênio } & \multicolumn{2}{|c|}{ Fósforo } & \multicolumn{2}{|c|}{ Cálcio } & \multicolumn{2}{|c|}{ Magnésio } \\
\hline & Copa & Tronco & Copa & Tronco & Copa & Tronco & Copa & Troncc \\
\hline \multicolumn{9}{|c|}{ (kg/ha) } \\
\hline 0 & 50,6 & 41,2 & 3,4 & 6,0 & 23,4 & 65,1 & 5,6 & 6,4 \\
\hline 30 & 77,2 & 46,8 & 6,0 & 5,7 & 35,0 & 64,4 & 8,1 & 9,7 \\
\hline 60 & 75,2 & 43,3 & 4,9 & 5,0 & 29,4 & 69,6 & 7,8 & 9,4 \\
\hline 120 & 85,0 & 56,9 & 6,1 & 8,2 & 37,3 & 97,1 & 9,7 & 12,1 \\
\hline 240 & 83,6 & 61,1 & 6,0 & 7,0 & 39,7 & 108,2 & 11,7 & 12,9 \\
\hline
\end{tabular}

Os valores de P no tronco e na copa são bem inferiores àqueles observados por Galo (1993) na primeira rotação, quando as plantas absorveram e acumularam maiores quantidades $(40,6 \mathrm{~kg}$ na parte aérea) deste nutriente, tendo em vista a aplicação de $2 \mathrm{t} / \mathrm{ha}$ de fosfatode-araxá ao solo e mais $100 \mathrm{~g}$ de superfosfato simples por planta. Já na segunda rotação, a não-reaplicação de fertilizante fosfatado em grande quantidade fez com que sua reduzida disponibilidade no solo não permitisse que as plantas acumulassem mais do que $14,3 \mathrm{~kg} / \mathrm{ha}$. A reduzida disponibilidade de $\mathrm{P}$ é também indicada pela elevação da eficiência de utilização de $\mathrm{P}$ do tronco das árvores na segunda rotação $(22.770 \mathrm{~kg} / \mathrm{kg}$, em média), em comparação com a primeira $(4.115 \mathrm{~kg} / \mathrm{kg})$. Tal fato indicaria uma redução relativa de $\mathrm{P}$ de 5,5 vezes na segunda rotação, maior do que qualquer outro nutriente analisado neste estudo.

A eficiência de utilização de $\mathrm{P}$ para produção de tronco e copa variou consideravelmente em função das doses de K aplicadas na implantação (Quadro 3). Os valores obtidos para essa característica, tanto para o tronco quanto para a copa, foram superiores aos observados na primeira rotação por Galo (1993), indicando haver menor disponibilidade de $\mathrm{P}$ no solo na segunda rotação. $\mathrm{O}$ aumento na eficiência de utilização de nutrientes indicaria a tendência de exaustão de nutriente no solo, como sugerido por Teixeira et al. (1989). Neste experimento, dos aproximadamente $230 \mathrm{~kg} / \mathrm{ha}$ de $\mathrm{P}$ total aplicados via adubos, uma proporção significativa não esteve disponível para as árvores.

A eficiência de utilização de K para o tronco e para a copa não foi alterada significativamente pelas doses de $\mathrm{K}$, mas apresentaram valores mais elevados do que os relatados por GALO (1993). Este autor estimou que a eficiência de utilização crítica (aquela correspondente à produção máxima de biomassa) de $\mathrm{K}$ para tronco era de $1.300 \mathrm{~kg} / \mathrm{kg}$. Os valores do Quadro 3 indicam deficiência mais acentuada de $\mathrm{K}$ nesta rotação. Fato semelhante foi observado para a eficiência de utilização de $\mathrm{Ca}$ e $\mathrm{Mg}$.

A eficiência de utilização de todos os nutrientes aqui determinados ( $\mathrm{P}, \mathrm{K}, \mathrm{Ca}$ e $\mathrm{Mg}$ ) no tronco foi bem superior aos valores preconizados como adequados por Barros et al. (1995). Segundo Santana (1994), valores muito elevados de eficiência ao final de um ciclo geralmente refletem maiores restrições no fornecimento dos nutrientes para as plantas, sendo forte indicativo de suas baixas disponibilidades no solo. Portanto, pode-se concluir que nesta segunda rotação a produção das brotações foi limitada por falta de nutrientes.

\subsection{Potássio Trocável no Solo e o seu Balanço no Ecossistema entre a Primeira e a Segunda Rotação}

Os maiores teores de $\mathrm{K}$ no solo, depois da segunda rotação (Quadro 4), foram constatados nos $20 \mathrm{~cm}$ superficiais, fato comumente observado em plantios florestais, em decorrência da ciclagem de nutrientes e da decomposição da manta orgânica e dos resíduos da colheita, processos e componentes que retornam significativa porção do nutriente ao solo. Os teores de $\mathrm{K}$ detectados na camada de $0-20 \mathrm{~cm}$ são baixos e insuficientes para manutenção de um incremento médio anual superior a $10 \mathrm{~m}^{3} / \mathrm{ha} / \mathrm{ano}$ (Novais et al., 1986). Nas demais camadas do solo, em especial abaixo de $20 \mathrm{~cm}$, os teores são extremamente baixos, o que determina concentrações na solução do solo incapazes de atender à demanda das plantas. 
Quadro 3 - Eficiência de utilização de P, K, Ca e Mg para copa e tronco em brotações de E. grandis, aos 80 meses de idade, influenciada pelo $\mathrm{K}$ aplicado na implantação

Table 3 - Efficiency of $P, K, C a$ and $M g$ utilization by coppices of $\boldsymbol{E}$. grandis for canopy and stem production, at the age of 80 months, as affected by $K$ rates, applied at planting time

\begin{tabular}{|c|c|c|c|c|c|c|c|c|}
\hline \multirow{2}{*}{ Dose de $\mathrm{K}_{2} \mathrm{O}$} & \multicolumn{2}{|c|}{ Fósforo } & \multicolumn{2}{|c|}{ Potássio } & \multicolumn{2}{|c|}{ Cálcio } & \multicolumn{2}{|c|}{ Magnésio } \\
\hline & Copa & Tronco & Copa & Tronco & Copa & Tronco & Copa & Tronco \\
\hline (kg/ha) & \multicolumn{8}{|c|}{ (kg de matéria seca/kg de nutriente absorvido) } \\
\hline 0 & 3.487 & 17.426 & 627 & 3.066 & 398 & 1.899 & 2.152 & 12.757 \\
\hline 30 & 3.188 & 24.401 & 630 & 2.899 & 463 & 2.407 & 2.282 & 12.994 \\
\hline 60 & 3.784 & 27.348 & 711 & 3.226 & 505 & 2.643 & 2.460 & 14.404 \\
\hline 120 & 4.247 & 20.944 & 708 & 2.492 & 522 & 2.094 & 2.287 & 12.473 \\
\hline 240 & 4.011 & 23.735 & 693 & 2.848 & 501 & 2.539 & 2.436 & 12.796 \\
\hline
\end{tabular}

Quadro 4 - Teores médios de K trocável em amostras coletadas a $50 \mathrm{~cm}$ do tronco da árvore e na entrelinha, a várias profundidades de solo, em brotações de $E$. grandis, aos 80 meses de idade, influenciados pelas doses de $\mathrm{K}$ aplicadas na implantação

Table 4-Average content of exchangeable $K$ in soil samples, collected from different depths, under 80 month-old, $\boldsymbol{E}$. grandis, as affected by $K$ rates, applied at planting time

\begin{tabular}{|c|r|r|r|r|r|}
\hline \multirow{2}{*}{ Profundidade } & \multicolumn{5}{|c|}{ Dose de $\mathrm{K}\left(\mathrm{kg} / \mathrm{ha}\right.$ de $\left.\mathrm{K}_{2} \mathrm{O}\right)$} \\
\cline { 2 - 6 } & 0 & 30 & 60 & 120 & 240 \\
\hline$(\mathrm{cm})$ & \multicolumn{5}{|c|}{$\left(\mathrm{mg} / \mathrm{dm}^{3}\right.$ de solo $)$} \\
\hline $00-10$ & 23,9 & 25,4 & 24,0 & 24,7 & 25,9 \\
$10-20$ & 17,4 & 18,6 & 18,6 & 17,8 & 18,7 \\
$20-40$ & 9,9 & 9,9 & 8,8 & 9,7 & 11,5 \\
$40-60$ & 4,7 & 4,4 & 5,7 & 5,6 & 4,7 \\
$60-100$ & 3,1 & 3,4 & 3,9 & 3,8 & 4,4 \\
$100-150$ & 2,9 & 2,8 & 3,6 & 4,1 & 3,4 \\
\hline
\end{tabular}

No que se refere ao balanço de K no ecossistema solo-planta, as árvores imobilizaram grande quantidade de K na parte aérea (tronco e copa), superior à que permaneceu no solo (Quadro 5). Em florestas tropicais, plantadas ou naturais, a existência de maior proporção de nutrientes na biomassa em comparação com o solo é fato comum (Novais \& Barros, 1997), o que reforça a importância da manutenção do máximo de resíduos florestais na área, para manutenção da sustentabilidade do ecossistema. Neste sentido, os dados deste experimento indicam que em um sistema de colheita em que fosse retirada toda a parte aérea do campo seriam retirados de 45 a $80 \mathrm{~kg} / \mathrm{ha}$ de $\mathrm{K}$, de acordo com o tratamento, com a média de $65 \mathrm{~kg} / \mathrm{ha}$ (Quadro 5). A quantidade de $\mathrm{K}$ exportada obviamente diminuiria com a intensidade da colheita, com valores médios de 38,7 e 19,1 kg/ha, se a colheita se restringisse ao tronco ou ao lenho, respectivamente. No caso mais comum, que é a colheita do tronco, permaneceriam na área cerca de $51,38 \mathrm{~kg} / \mathrm{ha}$ de $\mathrm{K}$, provenientes da copa, da manta e das raízes, em termos médios, que somados ao $\mathrm{K}$ existente no solo nas camadas de $0-150 \mathrm{~cm}$ de profundidade resultaria em 104,64 kg/ha de $\mathrm{K}$. A diferença do residual de $\mathrm{K}$ entre a maior dose de $\mathrm{K}$ aplicada e a testemunha foi de $48 \%$ para a primeira rotação e de $28 \%$ para a segunda rotação, demonstrando uma relação mais estreita entre os teores de K e também menores quantidades de $\mathrm{K}$ na segunda rotação.

Quadro 5 - Balanço de K na primeira e na segunda rotação em povoamento de $E$. grandis, influenciado pelas doses de $\mathrm{K}$ aplicadas na implantação

Table 5 - Potassium balance in the first and second rotations of $\boldsymbol{E}$. grandis, as affected by $K$ rates, applied at planting time

\begin{tabular}{|c|c|c|c|c|c|}
\hline \multirow{2}{*}{ Compartimento } & \multicolumn{5}{|c|}{ Dose de $\mathrm{K}\left(\mathrm{kg} / \mathrm{ha}\right.$ de $\left.\mathrm{K}_{2} \mathrm{O}\right)$} \\
\hline & 0 & 30 & 60 & 120 & 240 \\
\hline & \multicolumn{5}{|c|}{$(\mathrm{kg} / \mathrm{ha}$ de $\mathrm{K})$} \\
\hline & \multicolumn{5}{|c|}{ Primeira rotação ${ }^{1 /}$} \\
\hline Copa & 19,2 & 29,5 & 36,5 & 42,6 & 59,0 \\
\hline onco & 37,2 & 64,2 & 68,8 & 83,1 & 117,3 \\
\hline anta & 10,1 & 11,2 & 9,8 & 10,3 & 12,9 \\
\hline lo $(0-60)$ & 50,0 & 54,3 & 57,9 & 60,3 & 68,5 \\
\hline Adub & 47,3 & 47,3 & 47,3 & 47,3 & 47,3 \\
\hline Total $^{2 i}$ & 163,7 & 206,4 & 220,2 & 243,7 & 305,0 \\
\hline \multirow[t]{2}{*}{ K remanescente ${ }^{3 /}$} & 126,6 & 142,2 & 151,4 & 160,5 & 187,7 \\
\hline & \multicolumn{5}{|c|}{ Segunda rotação } \\
\hline Copa & 16,8 & 28,1 & 24,1 & 30,4 & 32,3 \\
\hline Tronce & 28,5 & 37,3 & 30,6 & 48,9 & 48,2 \\
\hline Manta & 6,4 & 5,0 & 5,5 & 7,9 & 10,5 \\
\hline Solo (0-60) & 70,5 & 72,6 & 71,6 & 73,1 & 77,0 \\
\hline Total & 122,2 & 143,1 & 131,8 & 160,3 & 167,9 \\
\hline K rem & 93,7 & 105,7 & 101,2 & 111,4 & 119,8 \\
\hline $\operatorname{Balancco}\left(2^{\mathrm{a}} \mathrm{R}-1^{\mathrm{a}} \mathrm{R}\right)$ & $-32,9$ & $-36,4$ & $-50,2$ & $-49,2$ & $-67,9$ \\
\hline
\end{tabular}

${ }^{1 /}$ Fonte: GALO (1993), ${ }^{2 /}$ Total = somatório do K da copa + tronco + manta + solo + adubação e ${ }^{3 /} \mathrm{K}$-remanescente $=$ total - tronco. 
Em um sistema de manejo em que as brotações não são adubadas o balanço de nutrientes é progressivamente negativo, como demonstrado pelo $\mathrm{K}$ remanescente no sistema, na primeira e na segunda rotação (Quadro 5). Esse déficit é mais acentuado à medida que maiores produtividades são obtidas. A condução de mais uma rotação na área deste estudo, sem a devida correção nutricional, resultará em produções ainda menores do que as obtidas neste estudo. Portanto, em solos com baixas reservas de nutrientes, como os de cerrado (Ricci, 1987), a manutenção da produtividade florestal requer a reposição dos nutrientes exportados pela colheita e perdidos por outros processos. A não-adoção dessa técnica é uma das causas da redução da produtividade de plantações de eucalipto em áreas com solos de baixa fertilidade, como os de cerrado.

\section{CONCLUSÕES}

O residual de K no solo em decorrência da adubação foi pequeno após a primeira rotação e não-proporcional às doses aplicadas. O reflexo da adubação feita no plantio sobre a produção das brotações foi decorrente da maior quantidade de resíduos florestais da primeira rotação e de seu conteúdo de $\mathrm{K}$.

A queda de produtividade de povoamentos de eucalipto em segunda rotação, na região do Vale do Jequitinhonha, pode ser atribuída à redução na fertilidade do solo devido à exportação de $\mathrm{K}$ e de outros nutrientes pela colheita do tronco na rotação anterior. No caso do $\mathrm{P}$, houve forte redução na eficiência do fosfato natural aplicado na época de plantio. A perda de produtividade da segunda rotação será tanto maior quanto maior for o índice de colheita.

\section{REFERÊNCIA BIBLIOGRÁFICA}

ASSOCIATIONS OF OFFICIAL ANALYTICAL CHEMISTS - A.O.A.C. Official methods of analysis of the Associations of Official Analytical Chemists. 12.ed. Washington, D.C.: 1975. 1024 p.

BARROS, N. F. et al. NUTRICALC 2.0 - Sistema para cálculo del balance nutricional y recomendación de fertilizantes para el cultivo de eucalipto. Bosque, v. 16, n. 1, p. 129-131, 1995.

BARROS, N. F.; NOVAIS, R. F.; NEVES, J. C. L. Fertilização e correção do solo para plantio de eucalipto. In: BARROS, N.F., NOVAIS, R.F. (Eds.). Relação SoloEucalipto. Viçosa, MG: Folha de Viçosa, 1990. p. 127-181.
BARROS, N. F.; TEIXEIRA, P. C.; TEIXEIRA, J. L. Nutrição e produtividade de povoamentos de eucalipto manejados por talhadia. Série Técnica - IPEF, v. 11, n. 30, p. 79-88, 1997.

BRAGA, J. M.; DEFELIPO, B. B. Determinação espectrofotométrica de fósforo em extratos de solos e plantas. Revista Ceres, v. 6, n. 1, p. 73-85, 1974.

CHAPIN, F. S. Ecological aspects of plant mineral nutrition. In: TINKER, B.; LAÜCHLI, A. (Eds.). Advances in plant nutrition. New York: Praeger Publishers, 1988. v. 3. p. 161-191.

EMPRESA BRASILEIRA DE PESQUISA AGROPECUÁRIA - EMBRAPA. Manual de métodos de análises de solo. 2.ed. Rio de Janeiro, SNLCS, 1997. $212 \mathrm{p}$.

GALO, M. V. Resposta do eucalipto à aplicação de potássio em solo de cerrado. Viçosa-MG: UFV, 1993. 40 p. Dissertação (Mestrado em Solos e Nutrição de Plantas) - Universidade Federal de Viçosa, 1993.

GAVA, J. L. Efeito da adubação potássica em plantios de E. grandis conduzidos em segunda rotação em solos com diferentes teores de potássio trocável. Série Técnica IPEF, v. 11, n. 30, p. 89-94, 1997.

GAMA-RODRIGUES, E. F. Carbono e nitrogênio da biomassa microbiana do solo e da serapilheira de povoamentos de eucalipto. Seropédica, Universidade Federal Rural do Rio de Janeiro 1997. 108 p. Tese (Doutorado em Ciência do Solo) - Universidade Federal Rural do Rio de Janeiro, 1997.

GONÇALVES, G. A. et al. Resposta na segunda rotação pela seleção efetuada na primeira, em famílias de meiosirmãos de Eucalyptus grandis Hill ex-Maiden. Revista Árvore, v. 21, n. 3, p. 377-383, 1997.

GONÇALVES, J. L. M. Interação genótipoambiente e relação entre a produtividade de sítios florestais de $E$. grandis e $E$. saligna com as propriedades de alguns solos do estado de São Paulo. Piracicaba: ESALQ/USP, 1990. 160 p. Tese (Doutorado em Solos e Nutrição de Plantas) - Escola Superior de Agricultura Luiz de Queiroz, 1990.

LADEIRA, B. C. Crescimento, produção de biomassa e eficiência nutricional de Eucalyptus spp., sob três espaçamentos, em uma seqüiência de idades. Viçosa-MG: UFV, 1999. 132 p. Dissertação (Mestrado em Ciência Florestal) - Universidade Federal de Viçosa, 1999.

R. Árvore, Viç̧osa-MG, v.26, n.5, p.577-584, 2002 
LEAL, P. G. L. et al. Produção de biomassa e absorção de nutrientes em Eucalyptus grandis influenciados pela aplicação de fosfato natural em solo de cerrado. Revista Árvore, v. 12, n. 2, p. 165-182, 1988.

McDONALD, A. G. S.; ERICSSON, T.; INGESTAD, T. Growth and nutrition of tree seedlings. In: RAGHAVENDRA, A. S. (Ed.). Physiology of Trees. New York, John Wiley \& Sons, Inc. 1991. p. 199-220.

MIRANDA, G. A. et al. Produtividade de povoamentos de eucalipto em regime de talhadia, em função da adubação parcelada, no Vale do Jequitinhonha - MG. Revista Árvore, v. 22, n. 1, p. 51-59, 1998a.

MIRANDA, G. A. et al. Produção de povoamentos de eucalipto em regime de talhadia, em função da adubação e da distribuição da galhada da rotação anterior, no Vale do Jequitinhonha - MG. Revista Árvore, v. 22, n. 3, p. 307314, 1998b.

NOVAIS, R. F.; BARROS, N. F. Sustainable agriculture and forestry production systems on acid soils: phosphorus as a case study. In: MONIZ, A.C. et al. (Ed.). Plant-Soil Interactions at Low pH: Sustainable Agriculture and Forestry Productions. Campinas: Sociedade Brasileira de Ciência do Solo. 1997. p. 39-51.

NOVAIS, R. F.; BARROS, N. F.; NEVES, J. C. L. Interpretação de análise química do solo para o crescimento de Eucalyptus spp. - níveis críticos de implantação e de manutenção. Revista Árvore, v. 10, n. 1, p. 105-111, 1986.

REIS, M. G. F.; BARROS, N. F. Ciclagem de nutrientes em plantios de eucalipto. In: BARROS, N. F.; NOVAIS, R. F. (Eds.) Relação solo-eucalipto. Viçosa-MG: Folha de Viçosa, 1990. p. 265-301.
REIS, M. G. F. et al. Acúmulo de biomassa em uma seqüência de idade de Eucalyptus grandis plantado no cerrado em duas áreas com diferentes produtividades.

Revista Árvore, v. 9, n. 2, p. 149-162, 1985.

RICCI, M. S. F. Capacidade de suprimento de potássio das diferentes frações granulométricas de alguns solos do estado de Minas Gerais. Viçosa-MG: UFV, 1987. 65 p. Dissertação (Mestrado em Solos e Nutrição de Plantas) Universidade Federal de Viçosa, 1987.

SANTANA, R. C. Crescimento e eficiência nutricional de procedências de Eucalyptus grandis e Eucalyptus saligna em sítios do estado de São Paulo. Viçosa-MG: UFV, 1994. 73 p. Dissertação (Mestrado em Solos e Nutrição de Plantas) - Universidade Federal de Viçosa, 1994.

STAPE, J. L.; BENEDETTI, V. Decréscimo de produtividade e resposta da brotação do Eucalyptus grandis à fertilização com macronutrientes em areia quartzosa no estado de São Paulo. In: CONFERÊNCIA IUFRO SOBRE SILVICULTURA E MELHORAMENTO DE

EUCALIPTOS, 1997, Salvador. Proceedings... Colombo: EMBRAPA - Centro Nacional de Pesquisa de Florestas, 1997. v. 3. p. 112-117.

TEIXEIRA, J. L. et al. Biomassa e conteúdo de nutrientes de duas espécies de eucalipto em diferentes ambientes do Médio Rio Doce, MG. Revista Árvore, v. 13, n. 1, p. 3450, 1989.

TEIXEIRA, P. C. et al. Nutrición potásica y relaciones hídricas en plantas de Eucalyptus spp. Bosque, v. 16, n. 1, p. 53-59, 1995. 